\title{
Ethanolic extract of Mucuna pruriens ameliorates carbon tetrachloride and rifampicin-induced hepatotoxicity and nephrotoxicity in wistar albino rat
}

\author{
Temidayo Ogunmoyole ( $\nabla$ temidayo.ogunmoyole@eksu.edu.ng ) \\ Ekiti State University, Ado Ekiti, Nigeria \\ Ola-Awe Ayomide Micheal \\ Ekiti State University, Ado Ekiti. Nigeria \\ Fatile Omotola Grace \\ Ekiti State University, Ado Ekiti, Nigeria
}

\section{Research Article}

Keywords: Biomarkers, exposure, antioxidant, nephroprotective, hepatoprotective

Posted Date: April 5th, 2021

DOI: https://doi.org/10.21203/rs.3.rs-320977/v1

License: (c) (1) This work is licensed under a Creative Commons Attribution 4.0 International License.

Read Full License 


\section{Abstract}

The present study investigates the hepatoprotective and nephroprotective potentials of Mucuna pruriens leaf extract with a view to providing a potent alternative in the management of liver and kidney diseases. Forty male albino rats were randomly placed into eight groups comprising five animals each. Animals in group I were administered with the distilled water, while groups II and VI were exposed to $\mathrm{CCl}_{4}$ and rifampicin respectively. Animals in groups III and IV were initially exposed $\mathrm{CCl}_{4}$ and treated with 50 and $100 \mathrm{mg} / \mathrm{kg}$ bw M. pruriens respectively. Similarly, groups VII and VIII animals were exposed to rifampicin and treated with 50 and $100 \mathrm{mg} / \mathrm{kg}$ bw M. pruriens respectively. Animals in group $\mathrm{V}$ were treated with 100 $\mathrm{mg} / \mathrm{kg}$ bw silymarin by oral gavage after an initial exposure to $\mathrm{CCl}_{4}$. Selected biomarkers of liver and kidney damage were determined in the serum and organs homogenate. Liver and kidney slices of experimental animals were also stained for histopathological examination. Exposure to $\mathrm{CCl}_{4}$ and rifampicin respectively resulted in marked distortion in lipid profile, inhibition of antioxidant enzymes and a surge in ALT, AST, ALP, urea, uric acid, bilirubin and creatine kinase. Treatment with M. pruriens extract reversed all deranged biochemical and histopathological parameters in a dose-dependent manner.

Restoration of both biochemical and histopathological alterations established the fact that M. pruriens is a potent hepatoprotective and nephroprotective plant, thereby giving credence to the potential usefulness of its leaf extract in the management of liver and kidney diseases.

\subsection{Introduction}

In recent times, oxidative stress concept has become an object of vast research attention [1]. It depicts deleterious alteration in the delicate balance between free radicals and antioxidants in the physiological system. Free radicals are highly reactive chemical species with an unpaired electron in the outermost shell. Being very reactive, free radicals can initiate oxidative damage to critical macromolecules such as proteins, nucleic acids, lipids and carbohydrates [1,2]. This damage is often triggered by abstracting electron from such macromolecules thereby oxidizing them. Endogenous free radicals (reactive oxygen species (ROS)) are produced majorly during aerobic respiration in the mitochondrial electron transport chain [3,4]. At the molecular level, oxidative stress has been traced to an upregulation of specific redox signaling pathways $[4,5]$. Its mechanism appears to vary from cell to cell. Generally, cells that are enrich with mitochondria are more vulnerable to oxidative stress than others [1]. Organelles such as mitochondria, microsomes, and peroxisomes of hepatocytes which are directly involved in free radicals' production could modulate specific signaling pathways. Peroxisome proliferator-activated receptor alpha (PPAR), mitogen-activated protein kinases (MAPK) and other protein kinases are said to upregulated during oxidative stress [6]. Specifically, upregulation of inflammatory cytokines such as interleukin-1 superfamily is the major molecular basis of hepatic damage [6-9]. Pathogenesis of hepatic injury has been linked to complex molecular interplay between oxidative stress and immune system [10,11]. Interestingly, a robust antioxidative system exists in the liver and kidney of all mammals including humans, to maintain the redox status of all critical macromolecules in the reduced form [1]. However, 
when the redox homeostasis in the liver, kidney and other vital organs is perturbed, oxidative stress sets in. Consequently, vital intracellular targets such as DNA, proteins, lipids are oxidatively attacked resulting in compromise of their functions. Signaling pathways of inflammations are then upregulated with its attendant devastating effects [6,12]. Oxidative stress can also be triggered by lipid peroxidation [13]. Oxidation of polyunsaturated fatty acids present in membranes can initiate a chain of free radicals which can in turn attack proteins leading to protein carbonylation $[6,14]$. Lipid peroxidation can be detrimental to critical membrane functions as a result of compromise in integrity and fluidity. Recently, free radical implicated peroxidation of membrane phospholipids has been linked to some chronic diseases including cancer, atherosclerosis, Parkinson diseases and aging[14]. Hence, a major strategy to mitigate the effects of these diseases is amelioration of oxidative damage by medicinal plants intervention [14].

M. pruriens Linn. (Fabaceae), has been used extensively as medicaments in the Ayurvedic and Indian system of medicine $[15,16]$. Its powdered seeds extract has been used to manage several oxidative stress implicated diseases, such as rheumatoid arthritis, diabetes, atherosclerosis, nervous disorders and sexual dysfunctions [17-19]. Its high level of (L-3,4 dihydroxyphenyl alanine (L-DOPA) have been suggested for its usage in the management of Parkinson's disease $[16,18]$. Presence of several phytochemicals with established antioxidant properties in $M$. pruriens extract has been linked to its numerous medicinal uses $[20,21]$. Considering, the medicinal potentials of $M$. pruriens, there is a dire need to investigate the therapeutic potential of its leaves as a viable alternative to conventional drugs used in the management of liver and kidney diseases.

\subsection{Materials And Methods}

\subsection{Plant Materials}

Fresh M. pruriens leaves were obtained within the University campus, botanically identified at the Department of Plant Science, Ekiti State University, Ado-Ekiti. The voucher specimen of the leaf with number UHAE2020070 was deposited at the University herbarium. The air-dried leaves were then powdered using a Warring blender. The weight of the powdered leaves was measured and stored in an airtight container.

\subsection{Reagents and Chemicals}

All reagents and chemicals were of high analytical grade obtained from standard commercial suppliers.

\subsection{Extraction of the extract}

M. pruriens leaves were air-dried for thirty (30) days at room temperature. The air-dried samples were ground to fine powder using a blender. $32.5 \mathrm{~g}$ of the powdered leaves was soaked in $100 \mathrm{ml}$ of $80 \%$ ethanol and left for $72 \mathrm{~h}$. It was then filtered using a cheese cloth to obtain a clear filtrate which was tightly covered with an insect-proof net and allowed for evaporation to dryness, which was monitored by 
weighing until a constant weight was obtained. The crude extract was kept airtight in a glass petri-dish inside a refrigerator and subsequently reconstituted with distilled water for animal treatment.

\subsection{Animals protocol}

Forty (40) wistar albino rats weighing $150 \mathrm{~g}-170 \mathrm{~g}$ were obtained from the animal house of the Department of Science Technology, The Federal Polytechnic, Ado-Ekiti and housed in clean wire meshed cages under standard conditions temperature $\left(24 \pm 1^{\circ} \mathrm{C}\right)$, relative humidity $(40-60 \%)$, and 12 / 12-hour light and dark cycle. They were allowed to have free access to food (commercial palletized diet from Vital Feed Mill) and drinking water ad libitum daily. The rat beddings were changed and replaced every day throughout the experimental period.

\subsubsection{Preparation of organs homogenate}

Animals were decapitated under cold-ether anesthesia and quickly dissected to obtain the liver, heart and kidney. They were trimmed of fatty tissue, washed in saline, blotted with filter paper and weighed. They were then chopped into bits and homogenized in ten volumes of the homogenizing phosphate buffer $(\mathrm{pH}$ 7.4) using a Teflon homogenizer. The resulting homogenates were centrifuged at $3000 \mathrm{rpm}$ at $4^{\circ} \mathrm{C}$ for 30 min. The supernatant obtained was collected and stored under $4^{\circ} \mathrm{C}$ and then used for biochemical analyses.

\subsubsection{Preparation of serum}

Whole blood collected from the heart into samples bottles and allowed to stand for $1 \mathrm{~h}$ to allow for coagulation. The coagulated blood was then centrifuged at $3000 \mathrm{rpm}$ for $15 \mathrm{~min}$ at $25^{\square} \mathrm{C}$ to obtain a clear supernatant which was carefully decanted and placed on ice for the estimation of serum biochemical parameters.

\subsection{Assay for Creatine Kinase (Ck-Mb) Activity}

Creatine kinase was assayed following the method previously described by Mattenheimer [22]. Briefly, 1.0 $\mathrm{ml}$ of imidazole buffer $(10 \mathrm{mM}, \mathrm{pH} 6.6)$ containing: creatine phosphate $(30 \mathrm{mM})$, glucose $(20 \mathrm{mM}), \mathrm{N}$ acetyl-cysteine $(20 \mathrm{mM})$, magnesium acetate $(10 \mathrm{mM})$, ethylene diaminetetraacetic acid (2 mM), ADP (2 $\mathrm{mM}), \operatorname{NADP}(2 \mathrm{mM}), \operatorname{AMP}(5 \mathrm{mM}), \operatorname{DAPP}(10 \mu \mathrm{M}), \mathrm{G} 6 \mathrm{PDH}(\geq 2.0 \mathrm{ku} / \mathrm{L})$ and $\mathrm{HK}(\geq 2.15 \mathrm{ku} / \mathrm{L}))$ was pipetted into a thermostated cuvette and incubated at $37^{\circ} \mathrm{C}$. Thereafter, $50 \mu \mathrm{l}$ of serum was added and thoroughly mixed. Absorbance of the resulting mixture at $340 \mathrm{~nm}$ was monitored for $5 \mathrm{~min}$ at $30 \mathrm{sec}$ interval.

\subsection{Assay of Aspartate Aminotransferase (AST) Activity}

Aspartate aminotransferase activity was determined as earlier described by Reitman and Frankel [23]. Briefly, $0.1 \mathrm{ml}$ each of serum and organ homogenates respectively was mixed with phosphate buffer (100 $\mathrm{mM}, \mathrm{pH} 7.4), \mathrm{L}$-aspartate $(100 \mathrm{mM})$, and a-oxoglutarate $(2 \mathrm{mM})$ and the mixture incubated for exactly 30 $\mathrm{min}$ at $37^{\circ} \mathrm{C}$. Five hundred microliters $(500 \mu \mathrm{l})$ of 2,4-dinitrphenylhydrazine $(2 \mathrm{mM})$ was added to the 
reaction mixture and allowed to stand for exactly $20 \mathrm{~min}$ at $25^{\circ} \mathrm{C}$. Thereafter, $5.0 \mathrm{ml}$ of $\mathrm{NaOH}(0.4 \mathrm{M})$ was added and left to stand for $5 \mathrm{~min}$. Absorbance was then read at $546 \mathrm{~nm}$ against the reagent blank.

\subsection{Assay of Alanine Amino transferase (ALT) Activity}

The principle previously described Reitman and Frankel [23] was followed in the assay of ALT using Randox kit. Five hundred microliters $(500 \mu \mathrm{l})$ of reagent 1 containing, phosphate buffer $(100 \mathrm{mM}, \mathrm{pH} 7.4)$, L-alanine $(200 \mathrm{mM})$ and a-oxoglutarate $(2.0 \mathrm{M})$ was added to $0.1 \mathrm{ml}$ of serum and each of the organ homogenates in a test tube and the mixture was incubated at $37^{\circ} \mathrm{C}$ for $30 \mathrm{~min}$. Exactly $0.5 \mathrm{ml}$ of reagent 2 containing, 2, 4-dinitrophenylhydrazine $(2.0 \mathrm{mM})$ was added and the solution incubated again at $20^{\circ} \mathrm{C}$ for $20 \mathrm{~min}$. Finally, $5.0 \mathrm{ml}$ of $\mathrm{NaOH}$ was added and the solution was allowed to stand for $5 \mathrm{~min}$ at room temperature and the absorbance measured at $546 \mathrm{~nm}$.

\subsection{Assay of Akaline Phosphatase (ALP) Activity}

Assay for ALP was based on the protocol described by Englehardt et al. [24]. Exactly $1.0 \mathrm{ml}$ of the reagent (1.0 M diethanolamine buffer $\mathrm{pH} 9.8,0.5 \mathrm{mM} \mathrm{MgCl}_{2}$; substrate: $10 \mathrm{mM}$-nitrophenol phosphate) was added separately to $0.02 \mathrm{ml}$ of serum and organs homogenates and mixed. The absorbance was taken at $405 \mathrm{~nm}$ for $3 \mathrm{~min}$ at $1 \mathrm{~min}$ interval.

\subsection{Estimation of Total Cholesterol Level}

Total cholesterol level was determined based on established method of Trinder [25]. Ten microliter each of standard, serum and organs homogenates were pipetted into labeled test tubes. Thereafter, $1.0 \mathrm{ml}$ of working reagent containing; Pipes buffer ( $80 \mathrm{mM} \mathrm{pH} 6.8)$, 4-aminoantipyrine $(0.25 \mathrm{mM})$, phenol $(6 \mathrm{mM})$, peroxidase $(\geq 0.5 \mathrm{U} / \mathrm{ml})$, cholesterol esterase ion $(\geq 0.15 \mathrm{U} / \mathrm{ml})$ and cholesterol oxidase $(0.10 \mathrm{U} / \mathrm{ml})$ was added into all the tubes. The test tubes were mixed thoroughly and incubated for $10 \mathrm{~min}$ at room temperature. Absorbance of the sample (Asample) was read at $500 \mathrm{~nm}$ against the reagent blank.

Cholesterol concentration $(\mathrm{mg} / \mathrm{dl})=$ Absorbance of sample/Absorbance of standard X Concentration of standard

\subsection{Evaluation of Concentration of Triglyceride}

Triglycerides level was measured as previously described by Tietz [26]. Ten microliters each of triglyceride standard, serum and organs homogenates were pipetted separately into labeled test tubes. Exactly $1.0 \mathrm{ml}$ of the working reagents; R1a (buffer) containing Pipes buffer $(40 \mathrm{mM}, \mathrm{pH} 7.6)$, 4-chloro-phenol (5.5 mM), magnesium-ion (17.5 mM); R1b (enzyme reagent containing 4-amino phenazone (0.5 mM), ATP (1.0 $\mathrm{mM})$, lipase $((\geq 150 \mathrm{U} / \mathrm{ml})$, glycerol-kinase $((\geq 0.4 \mathrm{U} / \mathrm{ml})$, glycerol-3-phosphate oxidase $((\geq 1.5 \mathrm{U} / \mathrm{ml})$ and peroxidase $(\geq 0.5 \mathrm{U} / \mathrm{ml})$ was added into all the tubes. The reaction mixtures were mixed thoroughly and incubated for $10 \mathrm{~min}$ at room temperature. Absorbance was measured at $546 \mathrm{~nm}$ against the blank. 
Triglyceride concentration $(\mathrm{mg} / \mathrm{dl})=$ Absorbance of sample/Absorbance of standard X Concentration of standard

\subsection{High Density Lipoprotein (HDL-c)-Cholesterol Assay}

Estimation of HDL-cholesterol was done as described by Grove [27]. Reaction mixture containing $200 \mu \mathrm{l}$ each of the serum and organs homogenates, $200 \mu \mathrm{l}$ of the cholesterol standard, $500 \mu$ l of the diluted precipitant R1 ( $0.55 \mathrm{mM}$ phosphotungstic acid, $25 \mathrm{mM}$ magnesium chloride) were mixed together and allowed to stand for $10 \mathrm{~min}$ at room temperature. It was then centrifuged for $10 \mathrm{~min}$ at $4000 \mathrm{rpm}$ to obtain a clear supernatant. The clear supernatant was separated off within $2 \mathrm{~h}$ and the cholesterol content was determined by the CHOD-PAP reaction method as follows:

One milliliter cholesterol reagent was added separately to $100 \mu$ leach of serum and organs homogenates and mixed together in a test tube. The standard test tube contained $100 \mu \mathrm{l}$ of the cholesterol standard supernatant and $1 \mathrm{ml}$ of cholesterol reagent. The reagent mixture was mixed thoroughly and incubated for $10 \mathrm{~min}$ at $25^{\circ} \mathrm{C}$. Absorbance of the sample $\left(\mathrm{A}_{\text {sample}}\right)$ and standard $\left(\mathrm{A}_{\text {standard }}\right)$ was then measured at $500 \mathrm{~nm}$ against the reagent blank within $1 \mathrm{~h}$.

\subsection{Low Density Lipoprotein (LDL) - Cholesterol Determination}

Concentration of low-density lipoprotein in the serum and organs homogenates was calculated as described as described by Friedwald et al. [28]:

LDL cholesterol $=$ Total cholesterol - Triglycerides/5 - HDL-cholesterol

\subsection{Determination of Catalase Activity}

Catalase activity was measured using the method previously described by Sinha [29]. Briefly, $200 \mu$ l each of serum and organs homogenates was mixed separately with $0.8 \mathrm{ml}$ distilled $\mathrm{H}_{2} \mathrm{O}$ to obtain a five-fold dilution. The assay mixture contained $2 \mathrm{ml}$ of solution $(800 \mathrm{mmol})$ and $2.5 \mathrm{ml}$ of phosphate buffer in a $10 \mathrm{ml}$ flat bottom flask. Five hundred microliters of appropriate dilution of the enzyme was rapidly mixed with the reaction mixture by a gentle swirling motion at room temperature. Thereafter, $1.0 \mathrm{ml}$ portion of the reaction mixture was withdrawn and blown into $1 \mathrm{ml}$ dichromate/acetic acid reagent at $60 \mathrm{~s}$ intervals. Hydrogen peroxide content of the withdrawn sample was determined by the method described below.

Catalase activity $=\mathrm{H} 2 \mathrm{O} 2$ Consumed $/ \mathrm{mg}$ protein

$\mathrm{H}_{2} \mathrm{O}_{2}$ consumed $=800-$ Concentration of $\mathrm{H}_{2} \mathrm{O}_{2}$ remaining

Concentration of $\mathrm{H}_{2} \mathrm{O}_{2}$ remaining was extrapolated from the standard curve for catalase activity.

\subsection{Determination of Superoxide Dismutase (SOD) Activity}


Superoxide dismutase activity was determined following the method of Misra and Fridovich [30]. An aliquot of a ten-fold dilution each of serum and organs homogenates was added separately to $2.5 \mathrm{ml}$ of $0.05 \mathrm{M}$ carbonate buffer ( $\mathrm{pH} 10.2)$ and allowed to equilibrate in a spectrophotometer. Reaction was initiated by the addition of $0.3 \mathrm{ml}$ of freshly prepared $0.3 \mathrm{mM}$ adrenaline to the mixture which was quickly mixed by inversion. The reference cuvette contained $2.5 \mathrm{ml}$ buffer, $0.3 \mathrm{ml}$ of substrate (adrenaline) and $0.2 \mathrm{ml}$ of water. Absorbance at $480 \mathrm{~nm}$ of the resulting solution was monitored for $150 \mathrm{~s}$ at $30 \mathrm{~s}$ interval.

\subsection{Determination of Reduced Glutathione (GSH) Level}

Previously established method of Beutler et al. [31] was followed in estimating the level of reduced glutathione (GSH). Exactly $0.2 \mathrm{ml}$ each of serum and organs homogenates was added separately to 1.8 $\mathrm{ml}$ of distilled water followed by the addition of $3.0 \mathrm{ml}$ of the precipitating solution and then shaken thoroughly. The mixture was then allowed to stand for $5 \mathrm{~min}$ and then filtered. One milliliter of filtrate was added of $4.0 \mathrm{ml}$ of $0.1 \mathrm{M}$ phosphate buffer $\mathrm{pH} 7.4$. Finally, $0.5 \mathrm{ml}$ of the Ellman's reagent was added to the mixture. A blank was prepared with $4.0 \mathrm{ml}$ of the $0.1 \mathrm{M}$ phosphate buffer, $1.0 \mathrm{ml}$ of diluted precipitating solution and $0.5 \mathrm{ml}$ of the Ellman's reagent. Absorbance of the resulting solution was then measured at $412 \mathrm{~nm}$ against reagent blank.

\subsection{Determination of Total Protein (TP) in Serum}

The Biuret method described by Weichselbaum [32] was employed in the determination of total protein. One milliliter of reagent R1 containing sodium hydroxide (100 mM), Na-K-tartrate $(18 \mathrm{mM})$, potassium iodide $(15 \mathrm{mM})$ and cupric sulphate $(6 \mathrm{mM})$ was added separately to $0.02 \mathrm{ml}$ each of serum and organs homogenates. The resulting mixture was incubated at $25^{\circ} \mathrm{C}$ and absorbance measured at $546 \mathrm{~nm}$ against the reagent blank.

\subsection{Lipid Peroxidation}

Thiobarbituric acid reactive substances (TBARS) content in the serum and organs homogenates were measured as previously described by Okhawa et al. [33] using Randox kits. One hundred microliters each of serum and organs homogenates were mixed separately with $2.5 \mathrm{ml}$ reaction buffer and boiled for $1 \mathrm{~h}$. The resulting mixture was centrifuged at 3,000 rpm for $10 \mathrm{~min}$. Absorbance of the supernatant obtained for each tube was then measured at $532 \mathrm{~nm}$. Malonidialdehyde (MDA) level in the supernatant was expressed as $\mu$ mole $\mathrm{MDA} / \mathrm{mg}$ protein using molar extinction coefficient of MDA-thiobarbituric chromophore $\left(1.56 \times 10^{5} / \mathrm{M} / \mathrm{cm}\right)$.

\subsection{Statistical Analysis}

Data are expressed as mean \pm SEM. Statistical evaluation was done using One-Way Analysis of Variance (ANOVA) followed by Duncan's Multiple Range Test (DMRT) by using SPSS 11.09 for windows. The significance level was set at $p<0.05$. 


\subsection{Results}

Animals exposed to $\mathrm{CCl}_{4}$ and rifampicin developed significant derangement in hepatic, renal and serum lipid profile (Table 1). This derangement was restored (in a dose-dependent manner) to a level comparable to animals that were not exposed to toxicants following treatment with $M$. pruriens extract (Table 1). Alkaline phosphatase (ALP), alanine transaminase (ALT) and aspartate transaminase (AST) activities were significantly depleted in the liver and kidney homogenates of experimental animals exposed to $\mathrm{CCl}_{4}$ and rifampicin (Table 2). However, oral treatment with $M$. pruriens extract restored the enzymes dose-dependently. Its effect was comparable to animals treated with silymarin (Table 2). Antioxidant enzymes (superoxide dismutase and catalase) were significantly inhibited in animals administered with $\mathrm{CCl}_{4}$ and rifampicin. Administration of $M$. pruriens extract resulted in a dose-dependent restoration of the antioxidant enzymes' activity (Table 3 ). This restoration was comparable with animals treated with silymarin (Table 3). Similar trend was observed regardless of organ (liver, kidney or serum) involved. (Table 3). Similarly, reduced glutathione (GSH) was significantly decreased in the serum and other tissue homogenates of experimental animals administered with $\mathrm{CCl}_{4}$ and rifampicin without treatment (Table 3). Administration of $M$. pruriens extract caused a dose-dependent amelioration and restoration of GSH level back to levels comparable with negative control and animals treated with the standard drug (Table 3). There was significant increase in total bilirubin (T. bil), urea, creatine kinase (CK) and uric acid in the serum and other organs homogenates following the administration of rifampicin and $\mathrm{CCl}_{4}$ without treatment (Table 4). Treatment with graded doses of $M$. pruriens extract resulted in a dosedependent restoration of these parameters to values comparable with the negative control and animals treated with the standard drug (Table 4).

Exposure to $\mathrm{CCl}_{4}$ and rifampicin respectively resulted in a significant increase in hepatic, renal and serum lipid peroxidation (Table 5). Treatment with $M$. pruriens markedly inhibited lipid peroxidation and restored it (in a dose dependent manner) to a level comparable with animals treated with silymarin (Table 5).

Table 1. Effects of $M$. pruriens extract on lipid profile in the liver and kidney of rats after $\mathrm{CCl}_{4}$ and rifampicin induced toxicity.

Data shows mean SEM values of four independent experiments performed in triplicate 'a' represents significant difference $(p<0.05)$ from the control, $(n=5)$.

Table 2. Effects of M. pruriens extract on selected biomarkers (AST, ALT and ALP) in the liver and kidney of rats after $\mathrm{CCl}_{4}$ and rifampicin induced toxicity.

Data shows mean SEM values of four independent experiments performed in triplicate 'a' represents significant difference $(p<0.05)$ from the control, $(n=5)$.

Table 3. Effects of M. pruriens extract on selected antioxidant enzymes (superoxide dismutase and Catalase) and reduced glutathione (GSH) in the liver and kidney of rats after $\mathrm{CCl}_{4}$ and rifampicin induced 
toxicity.

Data shows mean SEM values of four independent experiments performed in triplicate 'a' represents significant difference $(p<0.05)$ from the control, $(n=5)$.

Table 4. Effects of $M$. pruriens extract on selected biomarkers (urea, uric acid, creatine kinase, total bilirubin) in the liver and kidney of rats after $\mathrm{CCl}_{4}$ and rifampicin induced toxicity

Data shows mean SEM values of four independent experiments performed in triplicate 'a' represents significant difference $(p<0.05)$ from the control, $(n=5)$.

Table 5. Effects of $M$. pruriens extract on lipid peroxidation (MDA) level and total protein in the liver and kidney of rats after $\mathrm{CCl}_{4}$ and rifampicin induced toxicity

Data shows mean SEM values of four independent experiments performed in triplicate 'a' represents significant difference $(p<0.05)$ from the control, $(n=5)$.

Group I- Positive control; Group II- negative control (CCl 4 ); Group III - Animals treated with M. pruriens extract at $50 \mathrm{mg} / \mathrm{kg}$ bw after exposure to $\mathrm{CCl}_{4}$; Group IV - Animals treated with M. pruriens (100 mg/kg bw); Group V-Animals treated with silymarin (200 mg/kg bw) after exposure to $\mathrm{CCl}_{4}$. Group VI- Negative control (rifampicin). Group VII- Animals treated with M. pruriens (50 mg/kg bw) extract after exposure to rifampicin; Group VIII-Animals treated with M. pruriens (100 mg/kg bw) after exposure to rifampicin.

Figures (A-D) are representative photomicrograph of the liver slices of experimental animals showing a high-power magnification (x400 mag) of the inherent hepatocytes (black arrow head). Photomicrographs show the histomorphological manifestation of the hepatocytes, density of hepatocytes, distribution of hepatocytes, staining intensity of hepatocytes, size of central veins, content of central veins and expression of large vacuolations (dotted black circles). Large vacoulations with pick colouration are fatty livers with bile plaques which suggests cholestasis. Similarly, representative photomicrographs of the kidney slices (Figures E-G) of experimental animals showing a high-power magnification (x400mag) of renal corpuscle (black outline) which houses the glomerulus within the urinary space that is supplied by the afferent arteriole and drained by the efferent arteriole. The histomorphology presents with the convoluted tubule (CT), glomerular capillaries (GC) and inherent cells which include the intraglomerular podocytes $(P)$ as well as the juxtaglomerular cells and macula densa cells in the vascular poles of the renal corpuscles. The urinary pole continues out as the proximal convoluted tubules. A- liver slice of animals fed with animal feed and distilled water only; B- liver slice of animals administered with $3 \mathrm{ml} / \mathrm{kg}$ $\mathrm{CCl}_{4}$, without treatment; C- liver slice of animals induced with $3 \mathrm{ml} / \mathrm{kg} \mathrm{CCl}{ }_{4}$ and treated with $100 \mathrm{mg} / \mathrm{kg} \mathrm{M}$. pruriens; D - liver slice of animals administered with $3 \mathrm{ml} / \mathrm{kg} \mathrm{CCl}{ }_{4}$ and treated with 200mg/kg Silymarin; $E$ - kidney slice of animals administered with distilled water only; F - kidney slice of animals administered with $250 \mathrm{mg} / \mathrm{kg}$ rifampicin only without treatment; G- kidney slice of animals administered with $250 \mathrm{mg} / \mathrm{kg}$ rifampicin and treated with $100 \mathrm{mg} / \mathrm{kg} \mathrm{bw}$ of $\mathrm{M}$. pruriens 


\subsection{Discussion}

Carbon tetrachloride and rifampicin have been routinely used in animal model of hepatotoxicity and nephrotoxicity respectively [34]. However, in the present study, each of $\mathrm{CCl}_{4}$ and rifampicin exhibited toxicity to both kidney and liver tissues. This indicates that both toxicants are multiorgan specific.

Oxidative stress is the major culprit in the pathophysiology of $\mathrm{CCl}_{4}$-induced hepatotoxicity [35]. During metabolism, $\mathrm{CCl}_{4}$ is bioactivated to trichloromethyl free radical $\left(\mathrm{CCl}_{3}\right)$ in a serial process involving chloromethylation, saturation and peroxidation. Consequently, there is a progressive deterioration of membrane phospholipid of the hepatic endoplasmic reticulum. These processes eventually result to structural and functional disruption of hepatocytes [36,37]. In the present study, exposure to $\mathrm{CCl}_{4}$ resulted in a significant derangement in lipid profile of experimental animals. Total cholesterol, triglycerides and LDL were significantly elevated while HDL level was markedly depleted compared to negative control animals. The molecular event of $\mathrm{CCl}_{4}$-induced hepatic damage has been reported [38]. It involves the activation of several transcription factors such as NF-kB, activator protein 1 (AP-1) and early growth response 1 (EGR-1). Upon its activation, NF-kB triggers an upregulation of the inflammatory cascade by activating the release of specific proinflammatory cytokines [38]. Accumulation of inflammatory cytokines in hepatic cells then culminates in increased blood flow thereby resulting in liver inflammation ([38]. $\mathrm{CCl}_{4}$-induced hepatic inflammation has also been suggested to be linked to an alteration in the transcriptional expression of IL-6/STAT3 genes. Other mechanisms underlying $\mathrm{CCl}_{4}$-induced hepatic fibrosis has been reported [39]. The key feature of $\mathrm{CCl}_{4}$-induced fibrosis in the liver is the accumulation of extracellular matrix. Exposure to $\mathrm{CCl}_{4}$ increases tissue inhibitors of metalloproteinases (TIMP-1), activates transforming growth factor (TGF)- $\beta$ and inhibits nitric oxide formation. The consequence of these events is hepatic steatosis, fibrosis and cirrhosis [39]. Sympathetic nervous system (SNS) can also play a key role in $\mathrm{CCl}_{4}$ induced inflammatory responses that trigger hepatic injury. SNS has been found a culprit in the upregulation of ILs, monocyte chemoattractant protein - 1 (MCP-1/CCL2) and TNFa. These cytokines are the major inflammatory triggers of hepatic injury [39]. In the present study, $\mathrm{CCl}_{4}$ must have caused the derangement in lipid profile via these mechanisms. Treatment with $M$. pruriens extract, caused a dose-dependent restoration of triglycerides, cholesterol, HDL and LDL back to a level comparable to animals treated with silymarin. Anti-inflammatory potentials of flavonoids and other polyphenols have been extensively studied [40]. Flavonoids act by down regulating inflammatory transcriptional factors via the activation of transcription factor-3, activator protein-1 and CREB binding proteins. Hepatoprotective effect of $M$. pruriens can be attributed to the activation of TNF-induced NF-kB inhibition by its polyphenols [39]. In the present study, rifampicin exposure caused a significant alteration in renal lipid profile of experimental animals. Rifampicin acts by enhancing renal lipid peroxidation as well as inhibiting key detoxification enzymes [40]. Biotransformation of rifampicin in the liver leads to formation of a reactive toxic intermediate, deacetyl rifampin, which binds to critical macromolecules causing liver injury $[41,42]$. Treatment with $M$. pruriens extract reversed the toxicity imposed on renal lipid profile in a dose dependent manner. This effect can be attributed to the inhibition of ROS production by the polyphenolic content of the extract. 
Biomarker enzymes are important biochemical indicators of tissues functionality [43]. During organs damage, cellular enzymes such as AST, ALT, and ALP and bilirubin leak into the serum resulting in an elevation of their serum concentrations. Marked elevation in serum levels of ALP, AST and especially ALT are specific indicators of liver injury [44]. In the present study, there was a surge in serum level of ALT, AST and ALP following exposure to rifampicin and $\mathrm{CCl}_{4}$. This indicated toxicant-induced hepatocellular damage [45]. Studies have shown that rifampicin-induced hepatotoxicity and nephrotoxicity involves the activation of pregnane $X$ receptor (PXR). Activation of PXR triggers the upregulation of specific phase I and II enzymes such as GSTs, cytochrome $\mathrm{P}_{450}$ as well as ATP binding cassette (ABC) transporters [46]. Rifampicin has been suggested to induce the expression of hydrolases, and other enzymes, leading to an increased generation of hepatotoxic intermediates from isoniazid [46]. Similarly, rifampicin has been reported to contribute in no small measure to PXR-mediated derangement of heme biosynthesis resulting in the accumulation of hepatotoxic protoporphyrin IX [47]. Restoration of ALT, AST and ALP levels following M. pruriens treatment is indicative of its vast antioxidant potential. The restorative mechanism must involve inhibition of the activation of PXR receptor by polyphenolic component of the extract.

The devastating role of lipid peroxidation on human health has been reported [48]. Exposure to $\mathrm{CCl}_{4}$ and rifampicin resulted in a significant increase in malonidialdehyde (MDA) content in the serum and tissue homogenates of experimental animals. $\mathrm{CCl}_{4}$ has been identified with oxidative stress via inflammation. Biotransformation of $\mathrm{CCl}_{4}$ via the cytochrome $\mathrm{P}_{450}$ enzyme system results in the generation of hepatotoxic intermediates such as trichloromethyl and trichloroperoxyl radicals. These metabolites triggers lipid peroxidation with the production of hepatotoxic aldehydes responsible for liver injury [48]. $M$. pruriens treatment inhibited lipid peroxidation in a dose-dependent manner with potency comparable to the standard drug, irrespective of the organ involved. This suggests that $M$. pruriens leaves extract is a potential therapeutic alternative in the management of multi-organ disorders.

Activities of antioxidant enzymes are routinely used to monitor the health status of experimental animals. Marked decrease in SOD, CAT, creatine kinase and GSH levels was observed in animals challenged with $\mathrm{CCl}_{4}$ and rifampicin. In the liver, hepatotoxic metabolites of $\mathrm{CCl}_{4}$ and rifampicin metabolism bind to critical functional groups of antioxidant enzymes leading to their inhibition [48]. Treatment of exposed animals with $M$. pruriens extract restored these parameters in the serum and selected organs. The restorative mechanism is suggested to involve prevention of the toxic metabolites of rifampicin and $\mathrm{CCl}_{4}$, by polyphenols in the extract, from binding to critical groups on antioxidant enzymes.

Bilirubin, a product of hemoglobin degradation is usually excreted into the bile via conjugation involving UDP-glucuronyltransferase. Hence, an increase in bilirubin level in the blood is a marker of toxicity. Exposure of animals to $\mathrm{CCl}_{4}$ and rifampicin respectively, caused a significant increase in serum bilirubin. However, treatment with $M$. pruriens extract, caused a dose-dependent restoration of bilirubin. This observation adduced to the therapeutic potentials of the plant in the management of liver and kidney disorders. 
Urea has been used as a diagnostic tool to monitor the efficiency of dialysis procedure in patients with chronic kidney disease is urea [49]. Following exposure to $\mathrm{CCl}_{4}$ and rifampicin, there was a significant increase in serum urea level of animals. This suggests a free radical-induced dysfunction in ultrafiltration leading to urea retention. However, when treated with graded doses of $M$. pruriens, serum urea level was restored, in a dose-dependent manner. This is an indication that $M$. pruriens offers a promising potential in the management of kidney diseases.

Uric acid has been suggested as a culprit in the formation of gout and intricately linked with renal insufficiency and several other diseases including type II diabetes [50]. Exposure to $\mathrm{CCl}_{4}$ and rifampicin caused a significantly higher uric acid levels relative to the negative control. This may be related to free radical-induced up-regulation of purine metabolism. Treatment with $M$. pruriens extract restored the uric acid in the serum and organs homogenates to a level similar to the positive control animals. The restorative potential of $M$. pruriens was due to the prevention of an upregulation of purine catabolism by its phytochemicals.

Histopathological observation showed a distortion in the liver parenchymal histoarchitecture of animals administered with $\mathrm{CCl}_{4}$. This distortion was due to oxidative damage by $\mathrm{CCl}_{4}$. It manifested as severe hepatocellular necrotic vacuolation, cellular inflammation and congestion of central vein. These findings are in agreement with previous report on rodents [51]. Treatment with $M$. pruriens revealed a restoration of the hepatic histoarchitecture in a manner similar to silymarin-treated animals. Hence, M. pruriens protects against membrane permeability and alter drug-induced histopathological distortions. Similarly, exposure to rifampicin caused a severe distortion in the renal histoarchitecture. The onset progression and complications of kidney diseases has been linked to oxidative stress [52,53]. However, treatment with $M$. pruriens restored the renal histoarchitecture. This observation is consistent with earlier reports [54].

\section{Conclusion}

Biochemical and histopathological observations gave credence to the fact that $M$. pruriens is therapeutically potent. It can favorably compete with conventional drugs available for the treatment of liver and kidney diseases.

\section{Declarations}

All experimental protocols were approved by The Committee on Care and Use of Experimental Animals, Ekiti State University, Ado Ekiti, Ekiti State, Nigeria.

\section{Financial support}

This work was not funded by any organization, private or public.

Authors declare that there is no conflict of interest of any kind 
Acknowledgements

Authors wish to acknowledge the support of Department Medical Biochemistry, College of Medicine, Ekiti State University, Ado Ekiti, Nigeria.

\section{Data availability}

Data will be made available on request by the corresponding author.

\section{References}

[1] A.E. Azab, M.O. Albasha, A.S. Elsayed, Prevention of nephropathy by some natural sources of antioxidants, Yangtze Medicine 1 (2017) 235- 266.

[2] H. Cichoż-Lach, A. Michalak, Oxidative stress as a crucial factor in liver diseases, World J Gastroenterol 20(25) 2014 8082-8091

[3] S.I. Fox, Human Physiology. 16th Ed. McGraw-Hill Education. (2017) p. 666-670.

[4] A.A. Shahat, R. Ullah, A.S. Alqahtani, M.S. Alsaid, H.A. Husseiny, O. Al Meanazel Hepatoprotective effect of Eriobotrya japonica leaf extract and its various fractions against carbon tetra chloride induced hepatotoxicity in rats. Evid Based Complement Alternat Med. (2018) 3782768.

[5] A.L. Miranda-Vilelaa, F.A.Portilhoa, V. de Araujoa, The protective effects of nutritional antioxidant therapy on Ehrlich solid tumor-bearing mice depend on the type of antioxidant therapy chosen: histology, genotoxicity and hematology evaluations. J Nutr Biochem. 22 (2011) 1091-1098.

[6] Y. Yang, J. Chen, L. Yang, J. Song, Combination of metformin and luteolin synergistically protects carbon tetrachloride-induced hepatotoxicity: Mechanism involves antioxidant, anti-inflammatory, antiapoptotic, and Nrf2/HO-1 signaling pathway. Biofactors (2019): 1-9. DOI: 10.1002/biof.1521

[7] H. Tsutsui, X. Cai, S. Hayashi, Interleukin-1 family cytokines in liver diseases. Mediators Inflamm. (2015) 630265. doi: 10.1155/2015/630265

[8] C.A. Dinarello, Overview of the IL-1 family in innate inflammation and acquired immunity. Immunol Rev. 281 (2018) 8-27. doi: 10.1111/imr.12621

[9] A. Mantovani, C.A. Dinarello, M. Molgora, C. Garlanda, Interleukin-1 and related cytokines the regulation of inflammation and immunity. Immunity. 50 (2019) 778-95. doi:

10.1016/j.immuni.2019.03.012

[10] X. Jiang, H. Zhang, K, Mehmood, Protective effects of Herpetospermum caudigerum extracts against liver injury induced by carbon tetrachloride in mouse. J Biol Regul Homeost Agents 32 (2018) 699-704. 
[11] S. Dutta, A.K.Chakraborty, P. Dey, Amelioration of CCl4 induced liver injury in swiss albino mice by antioxidant rich leaf extract of Croton bonplandianus Baill. PLoS One.(2018) e0196411.

[12] L.W. Benjamin, J. Hartmut, Mechanisms of Inflammatory Liver Injury and Drug-Induced Hepatotoxicity. Curr Pharmacol Rep 4 (2018) 346-357.

[13] B. Halliwell, Biochemistry of oxidative stress. Biochem Soc Trans. 35 (2007) 1147-1150.

[14] A.A. Almokhtar, S.E. Ata, E.A. Azab, A.Q. Fawzia, Oxidative stress and antioxidant mechanisms in human body. J Appl Biotechnol Bioeng. 6(1) (2019) 43-47.

[15] P. Chawla, L. Bhandari, P.K. Sadh, R. Kaushik, Impact of solid-state fermentation Aspergillus oryzae) on functional properties and mineral bioavailability of black-eyed pea (Vigna unguiculata) Seed Flour. Cereal Chem 94(3) (2017) 437-442.

[16] F.M. Natasha, M. Harshvadan, C. Momodou, P. Gianni, W. Richard, C. Roberto, Could Mucuna pruriens be the answer to Parkinson's disease management in sub-Saharan Africa and other low-income countries worldwide? Parkinsonism and Related Disorders 73 (2020) 3-7.

[17] Y. Rajeshwar, M. Gupta, U.K. Mazumder, Antitumor activity and in vivo antioxidant status of Mucuna pruriens (Fabaceae) seeds against Ehrlich ascites carcinoma in Swiss albino mice. Iran J. Pharm Ther 4 (2005) 46-50.

[18] N.S. Chauhan, V. Sharma, V.K. Dixit, M.Thakur, A review on plants used for improvement of sexual performance and virility. BioMed Res int. (2014) 868062

[19] P. Ruhi, P. Chawla, H. Khan, K. Ravinder, A.K. Mohammed, An assessment of potential nutritive and medicinal properties of Mucuna pruriens: a natural food legume. Biotech 10 (2020) 261.

[20] L. Misra, H. Wagner, Extraction of bioactive principle from Mucuna pruriens seeds. Indian J Biochem Biophys 44 (2007) 56-60.

[21] V. Tumbas-Šaponjac, O.O. Akpoveso, O.I. Oyeniran, J. Desančić, D. Četojević-Simin, Antioxidant activity and enhanced cytotoxicity of aqueous Mucuna pruriens $\mathrm{L}$. leaf extract by doxorubicin on different human cancer cell lines. Phcog Mag 16 (2020) S224-8.

[22] H. Mattenheimer, Urinary enzyme measurements in the diagnosis of renal disorders. Ann Clin. Lab. Sci. 11(3) 1981 189-201.

[23] S. Reitman, S. Frankel, Glutamic - pyruvate transaminase assay by colorimetric method, Am. J. Clin. Path 28 (1957) 56-60.

[24] A. Englehardt A. Measurement of alkaline phosphatase. Aerztl Labor 16 (1970) 42 
[25] H. Trinder, A Simple Turbidimetric Method for the Determination of Serum Cholesterol. Ann. din. Biochem. 6 (1969) 165

[26] N.W. Tietz, Clinical Guide to Laboratory Tests, 3rd Edition, 1995;W.B. Saunders, Philadelphia.

[27] T.H. Grove, Effect of reagent pH on determination of high-density lipoprotein cholesterol by precipitation with sodium phosphotungstate-magnesium. Clin Chem 25(4) (1979) 560-564.

[28] W.T. Friedewald, R.I. Levy, D.S. Fredrickson, Estimation of the concentration of low-density lipoprotein cholesterol in plasma, without use of the preparative ultracentrifuge. Clin Chem.18 (1972) 499-502.

[29] A.K. Sinha, Colorimetric assay of catalase. Anal. Biochem.47 (1972) 389-394

[30] H.P. Misra, I. Fridovich, The role of superoxide anion in the autoxidation of epinephrine and a simple assay for superoxide dismutase. J. Biol. Chem. 247(15) (1972) 3170-3175

[31] E.D.O. Beutler, B.M. Kelly, Improved method for the determination of blood glutathione. J Lab Clin Med. 61 (1963) 882-890.

[32] T.E. Weichselbaum, An accurate and rapid method for the determination of protein in small amount of blood, serum. Am J Clin Pathol (1995) 1640

[33] H. Ohkawa, H. Ohishi, K. Yagi, Assay for lipid peroxide in animal tissues by thiobarbituric acid reaction. Anal. Biochem. 95 (1979) 351-358.

[34] S. Li, H.Y. Tan, N. Wang, Z.J. Zhang, L. Lao, C-W. Wong, Y. Feng, The role of oxidative stress and antioxidants in liver diseases. Int J Mol Sci 16 (2015) 26087-26124.

https://doi.org/10.3390/ijms161125942.

[35] M.M. Hafez, O.A. Al-Shabanah, N.O. Al-Harbi, M.M. Al-Harbi, S.S. Al-Rejaie, S.M. Alsurayea, M.M. Sayed-Ahmed, Association between paraoxonases gene expression and oxidative stress in hepatotoxicity induced by $\mathrm{CCl}_{4}$. Oxid Med Cell Longev (2014) 1-12.

[36] K. Abbas, G.H. Rizwani, H. Zahid, T.M. Javed, Evaluation of hepatic activity of various morphological parts of Musa paradisiaca L. Afr J Pharm Pharmacol 10(19) (2016) 419-29.

[37] H. Ali, N. Kabir, A. Muhammad, M.R. Shah, S.G. Musharraf, N. Iqbal, S. Nadeem, Hautriwaic acid as one of the hepatoprotective constituent of Dodonaea viscosa. Phytomed 21 (2014) 131-40.

[38] R. Valenzuela, A.V. Luis, Impact of the Co-Administration of N-3 Fatty Acids and Olive Oil Components in Preclinical Nonalcoholic Fatty Liver Disease Models: A Mechanistic View. Nutrients 12 (2020) 499; doi:10.3390/nu12020499 
[39] S.A. Soto-Alarcón, V. Rodrigo, V. Alfonso, A.V. Luis, Liver Protective Effects of Extra Virgin Olive Oil: Interaction between Its Chemical Composition and the Cell-signaling Pathways Involved in Protection. Endocrine, Metabolic and Immune Disorders - Drug Targets 18 (2018) 75-84

[40] H. Kalantari, A.A. Hemmati, N. Bavarsad, A. Rezaie, S. Ahmadi, Effect of topical nanoliposomes of paromomycin on rats liver and kidney. Jundishapur J Nat Pharm Prod. 9 (2014) e17565.

[41] A. Ramasamy, J. Nandhakumar, D. Saibal, A. Swapna, P.A. Alice, B. Preeti, B. Dinesh, Evaluation of the Protective Role of Glycine max Seed Extract (Soybean Oil) in Drug-Induced Nephrotoxicity in Experimental Rats. J Dietary Suppl (2017) https://doi.org/10.1080/19390211.2017.1358792

[42] Y.M. Shalaby, T.M. Esther, S.A. Samar, S.A. Azza, Involvement of Nrf2/HO-1 antioxidant signaling and NF-KB inflammatory response in the potential protective effects of vincamine against methotrexateinduced nephrotoxicity in rats: cross talk between nephrotoxicity and neurotoxicity. Arch Toxicol (2019) https://doi.org/10.1007/s00204-019-02429-2

[43] R. Zhu, W. Yajing, L. Zhang, G. Qinglong Oxidative stress and Liver disease. Hepatol Res 2012; 42(8): 741-749. doi:10.1111/j.1872-034x.2012.00996.x.

[44] K.V. Anand, R. Anandhi, M. Pakkiyaraj, P. Geraldine, Protective effect of Chrysion on carbon tetrachloride $\left(\mathrm{CCl}_{4}\right)$-induced tissue injury in male wistar rats. Toxicol Ind Health 27(10) (2011) 923-33.

[45] Y.J. Chen, P. Chou, C.L. Hsu, J. Hung, Y. Wu, J. Lin, Fermented citrus lemon reduces liver injury induced by carbon tetrachloride in rats. Evid Based Complement Alternat Med (2018) 1-10.

[46] W. Yue-Ming, C.C. Sergio, T.B. Christopher, C. Taoshen, Pregnane X receptor and drug-induced liver injury Expert Opin. Drug Metab. Toxicol. 10(11) (2014)

[47] S. Li, H.Y. Tan, N. Wang, Z.J. Zhang, L. Lao, C-W. Wong, Y. Feng, The role of oxidative stress and antioxidants in liver diseases. Int J Mol Sci 16 (2015) 26087-26124.

https://doi.org/10.3390/ijms161125942.

[48] V.R. Kota, S. Srivastava, S.S. Singhal, Lipid Peroxidation Products in Human Health and Disease. Oxidative Med and Cellular Longev (2019), Article ID 7147235, https://doi.org/10.1155/2019/7147235

[49] C. Almeras, A. Argiles, The general picture of uremia. Semin Dial 22 (2009) 329-333

[50] A.J. Safi, Mahmood R, Khan MA, Haq AU. Association of Serum Uric Acid with Type 2 Diabetes Mellitus. J Pak Med Ins 18(1) (2004) 59-63.

[51] N. Huda, A. Mosadik, A. Awal, S. Rahman, Hepatoprotective Activity of Sharbat deenar against carbon tetrachloride induced hepatotoxicity in rats. Int. J Pharmacol Pharm Sci. 8(12)

2014doi.org/10.5281/zenodo.1316253 
[52] R. Zhu, W. Yajing, L. Zhang, G. Qinglong, Oxidative stress and Liver disease. Hepatol Res 42(8) (2012) 741-749. doi:10.1111/j.1872-034x.2012.00996.x.

[53] R.N. Jadeja, V.D. Ranjitsinh, N. Srinivas, Oxidative Stress in Liver Diseases: Pathogenesis, Prevention, and Therapeutics. Oxidative Med Cell Long (2017) doi.org/10.1155/2017/8341286

[54] I.K. Sundaram, S. Deepika, S. Vignesh, G. Shinomol, S. M. Sahabudeen, Poly herbal formulation with anti-elastase and anti-oxidant properties for skin anti-aging. BMC Compl Alt. Med 18 (2018) 33 DOI $10.1186 /$ s12906-018-2097-9

\section{Tables}

Tables 1-5 were not provided with this version of the manuscript.

\section{Figures}

Figures A-G were not provided with this version of the manuscript.

\section{Figure 1}

Figures A-G were not provided with this version of the manuscript. 